\title{
DISCUSSION ON THE PROBLEM OF REGULARIZED RECONSTRUCTION IN HBIM1
}

\author{
D. $\mathrm{Li}^{1}, \mathrm{X}$. Wang ${ }^{1}, \mathrm{C} . \mathrm{Bai}^{2}, \mathrm{C} . \mathrm{Wu}^{1, *}$ \\ ${ }^{1}$ School of Architecture, Tianjin University, 92 Weijin Rd, Nankai District, Tianjin, P. R. China - (790806480, \\ wangxi88love)@qq.com; wucong@tju.edu.cn \\ ${ }^{2}$ School of Civil Engineering, Tianjin University, 92 Weijin Rd, Nankai District, Tianjin, P. R. China - Babybcj@ sina.com
}

\section{Commission II, WG II/8}

KEY WORDS: HBIM, regularity, differentiation; regularized reconstruction, index frame model

\begin{abstract}
:
In heritage recording, conservators are required to understand the subjects, that, in a sense, means to recognizing the two opposite aspects of the buildings in question: regularity and differentiation. To do a specific documentation work, one has to make balance between regularity and differentiation -- the opposite poles, according to the goals and specific needs of the work. This paper discuss the goals and needs of HBIM, and regards HBIM models as "index frames" to run the information management for heritage. Therefore regularity is preferred in HBIM and the question of "regularized reconstruction" are raised. Three examples are provided to demonstrate how to realize the representation of regularity in preparing HBIM models, resulting in the conclusion: 1) partial or global regularized reconstruction is available and efficient; 2) regularized reconstruction can make best use of the advantages of BIM and bypass the disadvantages; 3 ) to what extent the use of regularized reconstruction depends on the regularity degree of the subject.
\end{abstract}

\section{OPPOSITE ASPECTS OF HERITAGE: REGULARITY AND DIFFERENTIATION}

\subsection{Regularity and Differentiation}

When doing heritage documentation, you can never or do not need to $100 \%$ or put everything into your recording media due to technical limitations and practical needs. To meet the needs, documentation workers are usually required to understand as much as possible the building or site in question, and to understand why and what you are recording.

In a sense, one of the dimensions of understanding can be interpreted as recognizing the two opposite aspects of your subject: REGULARITY and DIFFERENTIATION (Table 1), which are explained in Table 1.

\begin{tabular}{|l|l|l|}
\hline & \multicolumn{1}{|c|}{$\begin{array}{c}\text { Recording } \\
\text { Differentiation }\end{array}$} & \multicolumn{1}{c|}{$\begin{array}{c}\text { Recording } \\
\text { Regularity }\end{array}$} \\
\hline Basis & Coordinates & $\begin{array}{l}\text { Relationships } \\
\text { (associative, constraint, } \\
\text { and parametric) }\end{array}$ \\
$\begin{array}{l}\text { Representation } \\
\text { focus }\end{array}$ & Superficial phenomena & Intrinsic essence \\
Meanings & $\begin{array}{l}\text { Lack of architectural } \\
\text { semantic meaning }\end{array}$ & $\begin{array}{l}\text { Architectural semantic } \\
\text { meaning included }\end{array}$ \\
\hline
\end{tabular}

Table 1. Comparison of recording "differentiation" and "regularity"

\subsection{As found or as designed?}

To what extent you think of them may affluence your final expression of your subjects, representing it "as found," "as built," "as designed," or sometimes "as conceived."

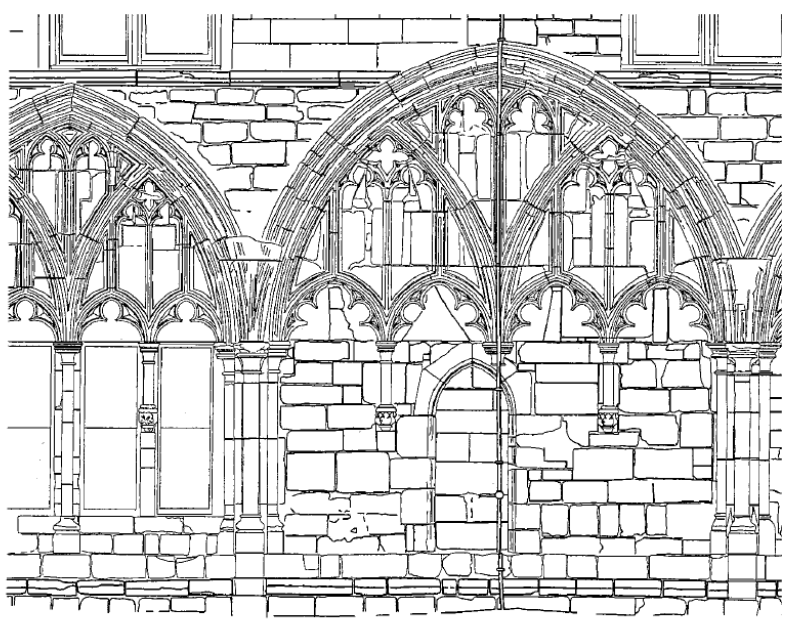

Figure 1. Stone by stone records for Battle Abbey, photogrammetric survey (after English Heritage, 2000)

If you prepare a drawing as found, as most conservators usually do in Europe, you must emphasize the differentiation aspects of your subject. This practice seems to come from disciplinary requirements of surveyors, who try their best to acquire "accurate" coordinate data (Figure 1). If everything is subject to its coordinates, as what a point cloud view shows us, it naturally gets to its extreme in the differentiation aspect (Figure 5). This

\footnotetext{
${ }^{1}$ This paper supported by National Natural Science Foundation of China: (Project no. 51878440)

* Corresponding author
} 
is also a tradition of archaeologists, who usually are supposed to solve grand puzzles and have to depict their sites as found because they do not know exactly what they are drawing at the beginning (Figure 2). The modern conservation philosophy emphasize the preservation of diversity of values, which also lead to the encouragement of recognizing and representing the differentiation aspect of the building concerned (Figure 1). Last, the complexity and irregularity of the shapes of some buildings or ruins themselves, certainly lead to as-found drawings for them (Figure 6).

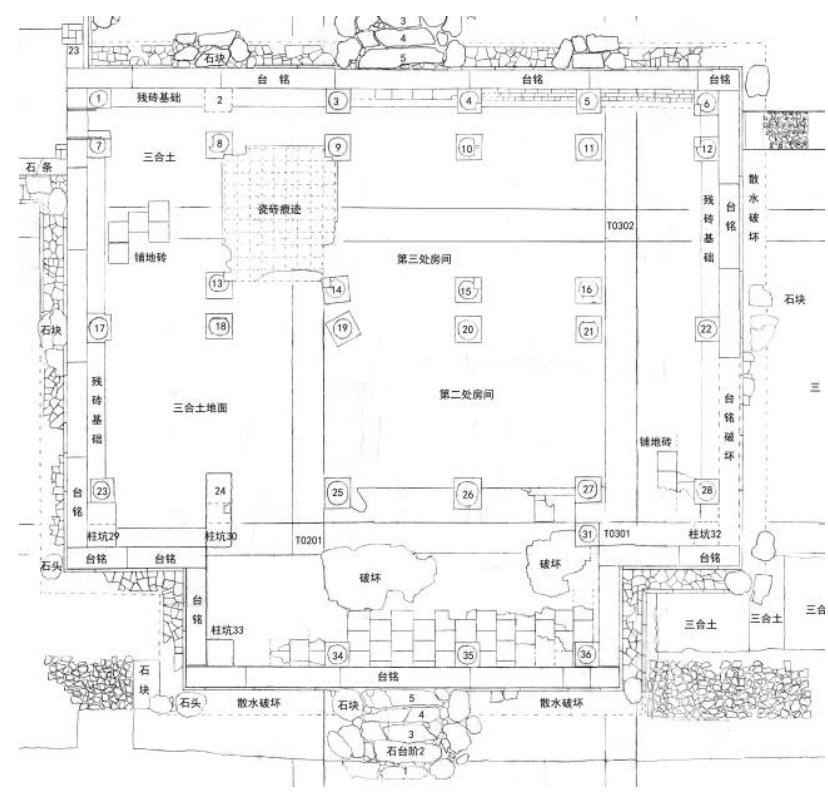

Figure 2. Archaeological site plan of Ruyuan Garden, the Summer Palace, Beijing

On the other hand, some researchers tend to find and represent the intrinsic relationships revealed or concealed in the building fabrics, resulting in some kinds of drawings as designed or as conceived. This makes sense because recording work itself is a kind of "reverse engineering", and its final objectives include but are not limited to revealing the principles and logic of design, construction and structure, to summarize the stylistic characteristics and cultural associations, etc (Figure 3, 4).

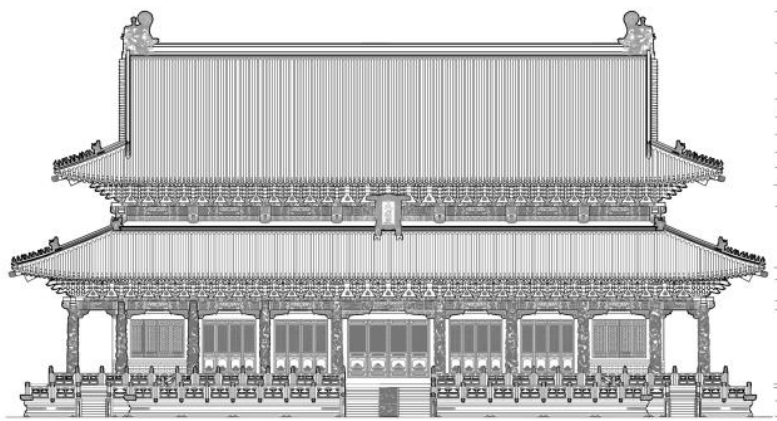

Figure 3. Front Elevation of the Hall of Great Achievements, Confucian Temple, Qufu, measured and drawn by Tianjin University

\section{BALANCE BETWEEN RECORDING REGULARITY AND DIFFERENTIATION}

In fact, to do a specific documentation work, one has to make balance between the opposite poles: regularity and differentiation, according to the goals and specific needs of the work.
Figure 4 is a one of the measured drawings prepared by a team from École française d'Extrême-Orient (EFEO), Paris, in 1970s (Dumarçay, 1971). This is a kind of compromise between regularity and differentiation. In this case, differentiation seemed to gave way to regularity, because every horizontal lines are absolute "horizontal", which caught the characteristics of Angkor masonry.

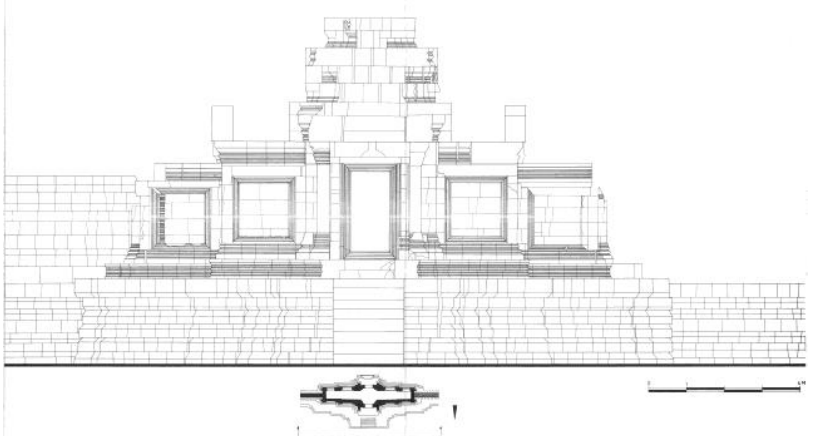

Figure 4 North elevation of the Outer North Gate of Ta Keo Temple, Angkor Monuments, Cambodia (after Dumarçay, 1971)

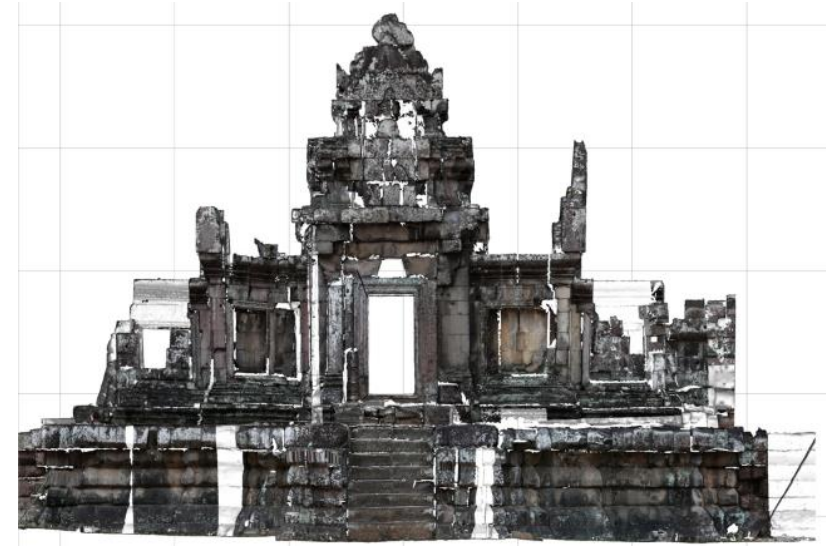

Figure 5. South elevation of the Outer South Gate of Ta Keo Temple, Angkor Monuments, orthophoto based on point cloud

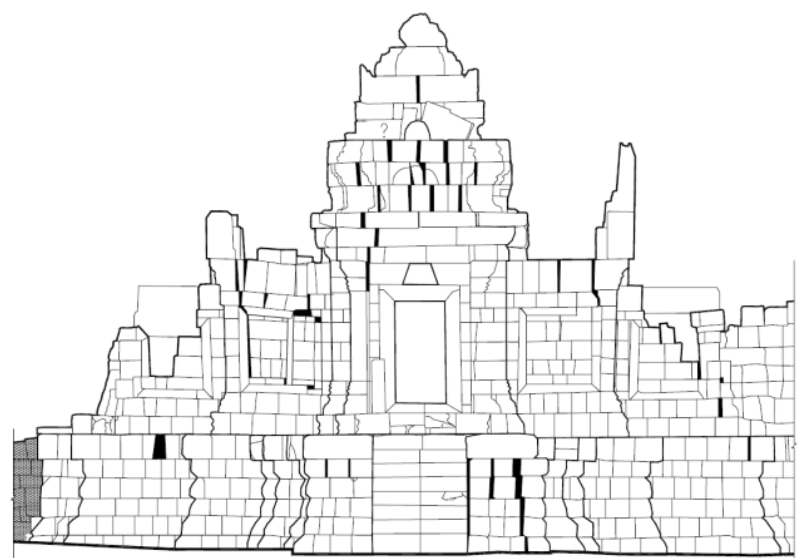

Figure 6. South elevation of the Outer South Gate of Ta Keo Temple, Angkor Monuments, Cambodia, measured drawing based on point cloud and orthophoto 


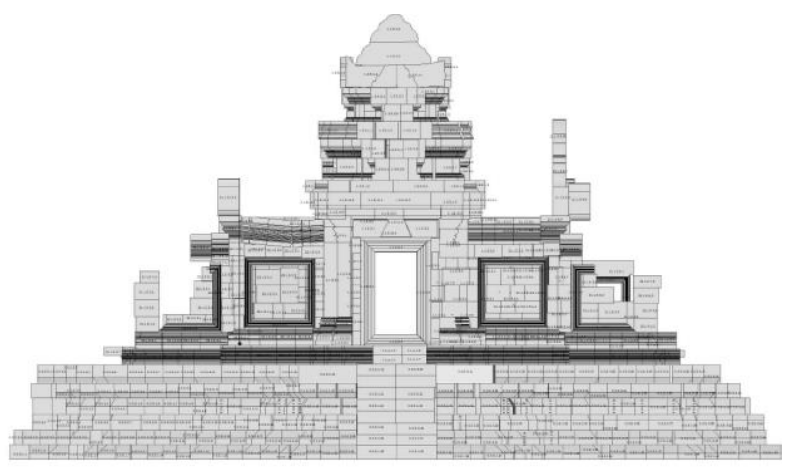

Figure 7. South elevation of the Outer South Gate of Ta Keo Temple, Angkor Monuments, Cambodia, generated from BIM model.

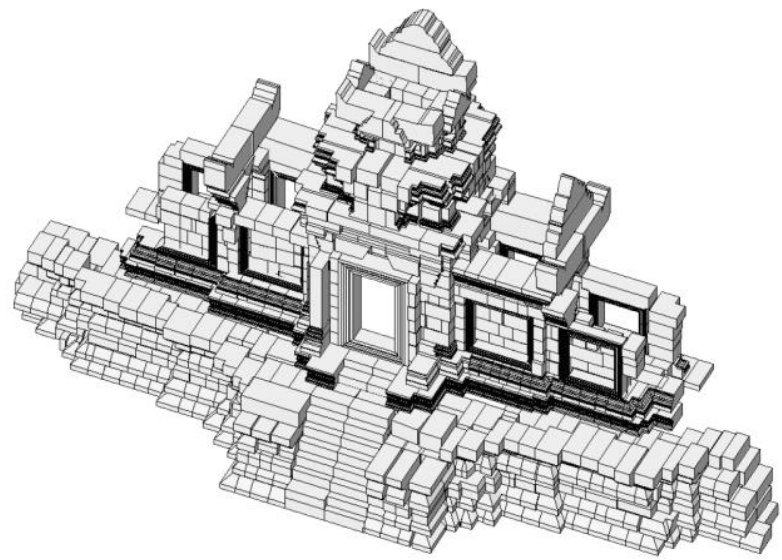

Figure 8. BIM model for the Outer South Gate of Ta Keo Temple, Angkor Monuments, Cambodia

Around 2010, we undertook the recording project of Ta Keo for the Conservation and Restoration Project of Ta Keo in Cambodia Angkor Monuments. We did it in two ways: traditional measured drawings and BIM model, both based on 3D laser scanning (Figure 5). In preparing measured drawings, we focused on the differentiation aspect (Figure 6), While in BIM, we had to represent it in a more compromised way as what EFEO did 40 years ago (Figure6, 7), because we found that BIM itself is developed to express regularities and logics of architectural design and construction.

\section{HBIM: REGULARITY PREFERRED}

In our opinion, HBIM model is regarded as a sustainable frame of index for heritage information management (Figure 9), an archetypal or ideal model which is built with a set of "sampling sizes," representing specific form, material, style of the building while ignoring detailed, subtle differentiations: deforms, defectives or irregularities. Based on this framework, other properties, information and related analysis, calculation could be searched, tagged, indexed, attached or externally linked, and updated. (Wu C. 2016)

From this description of HBIM, focus tends to be put on the regularity aspect of the subject, while other recording methods and outputs such as point cloud, mesh models, as-found drawings, which in turn can be integrated into BIM system, are used to representing the differentiation aspect. On the other hand, BIM itself does well in representing regular relationships, and if there are too many differentiation elements to be recorded, such as irregular column positions and heights will lead to too many titling or leaning beams, purlins and rafters, possibly resulting in a failure of modeling.

Thus, for the reasons of BIM's advantage and the feasibility of modeling, the problem of regularized reconstruction is hereby raised.

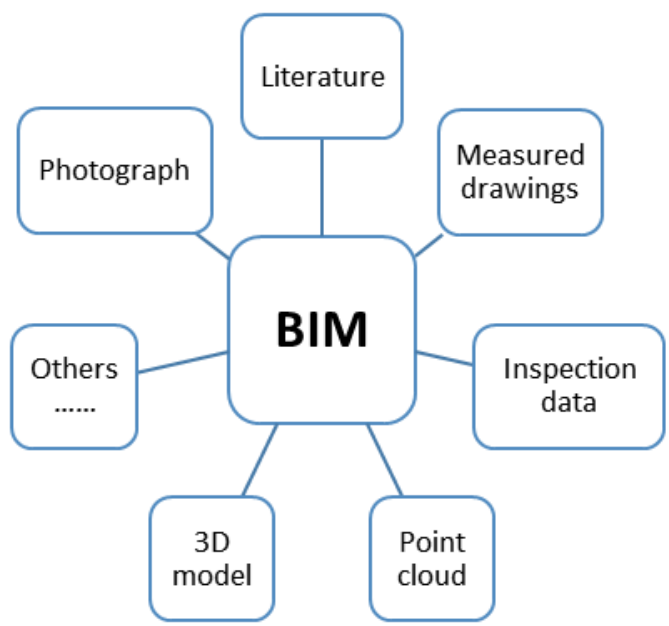

Figure 9. BIM model as an "index frame"

\section{THREE EXAMPLES OF REGULARISED RECONSTRUCTION}

Three examples are selected here to demonstrate the application of regularized reconstruction by parametric modelling application such as Grasshopper. All resulting models will be converted to BIM models afterwards.

\subsection{Regularized Reconstruction for grid system}

Almost every building has its own grid system as its unique part of space framework. But from point cloud data, you will never get a regularized grid because errors always occur during the process of component making, installation of components, and the process of measurement, resulting position deviations of the columns in a row, for example, in a traditional Chines timber structure.

Building: Main Hall of Jingfu Palace, Palace Museum, Beijing (Figure 10)

Objective: regularized Reconstruction Grid system for columns

\section{Solution:}

1 Acquiring the bottom center point of each column fitting from point cloud data (Figure 11)

2 Predefined conditions: rectangular grid, deviation less than $64 \mathrm{~mm}$

3 Reconstruction of the grid by genetic algorithm in Grasshopper (Figure 12)

4 Applying the grid data in a BIM software to start the process of modelling (Figure 13)

In this case, the grid system is enforced to be regularized as a rectangular system to depict its original design logic. 


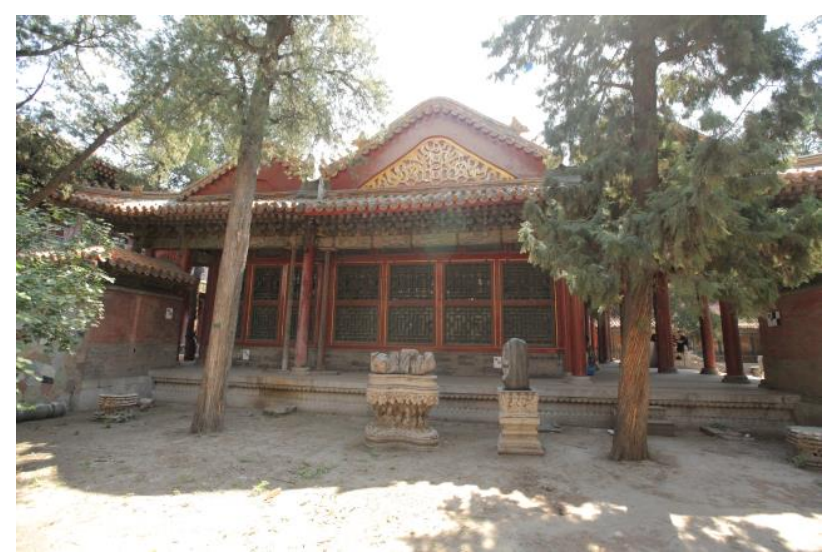

Figure 10. Main Hall of Jingfu Palace, Forbidden City (the Place Museum), Beijing

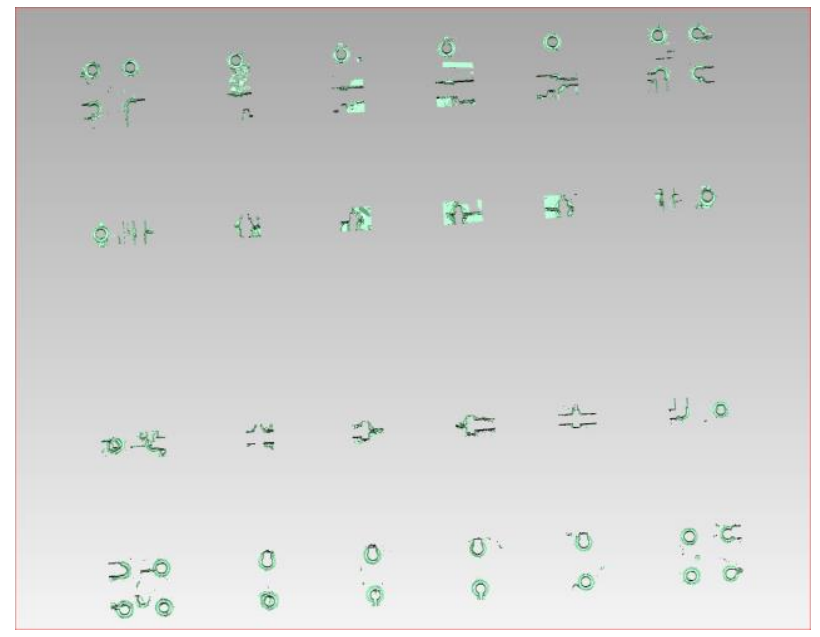

Figure 11. Columns of the Main Hall of Jingfu Palace, Forbidden City (the Place Museum), Beijing, point cloud segment

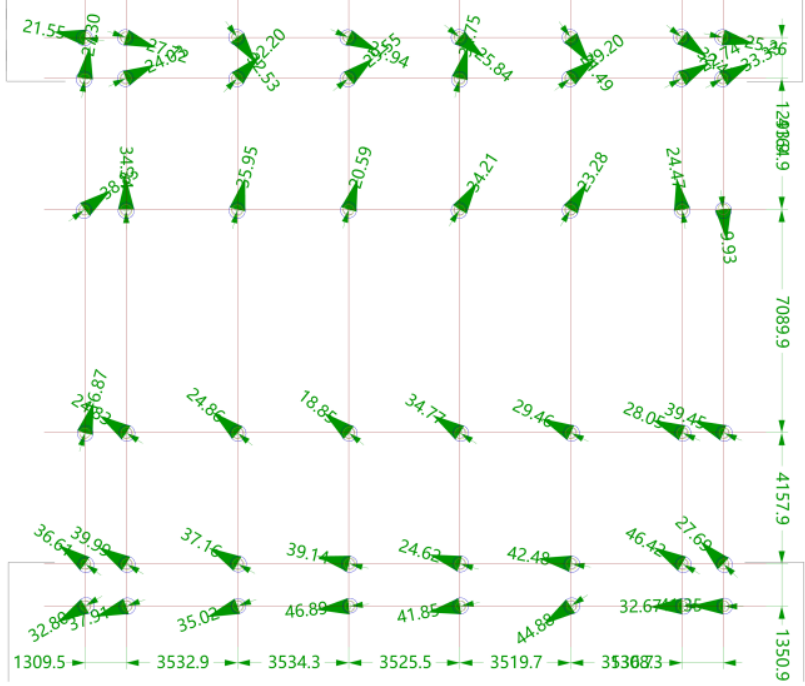

Figure 12. Grid system generated for the Main Hall of Jingfu Palace, Forbidden City (the Place Museum), Beijing

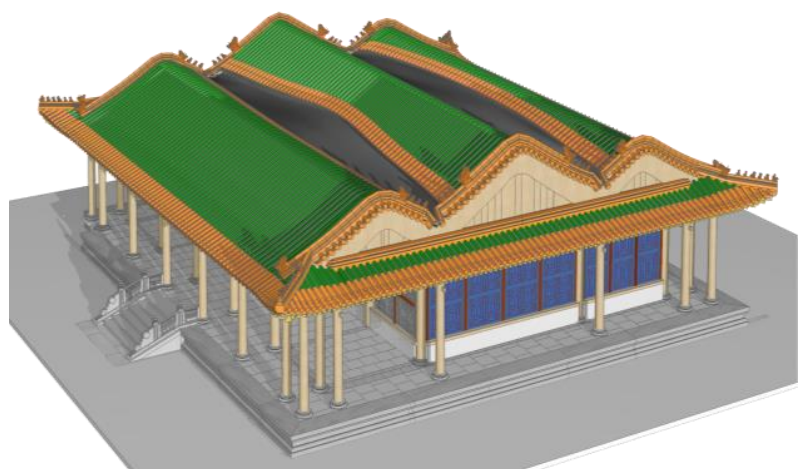

Figure 13. BIM model for the Main Hall of Jingfu Palace, Forbidden City (the Place Museum), Beijing

\subsection{Regularized Reconstruction for Roofing tiles}

In traditional Chinese architecture, large roof is one of the characteristics, which is regarded as the "fifth face." However, roofs are usually composed of a great number of tiles and other members. Do we need to build it tile by tile in a BIM modle?

Building: the Main Hall of Lu Ban Shirne, Jizhou District, Tianjin

Objective: regularized reconstruction of its roofing tiles

Difficulty: doubly curved surface covered by rows of tiles

\section{Solution:}

1 Extracting skeleton lines from point cloud (regular or irregular) (Figure 14, 15)

2 Generating the roof surface from the skeleton lines in Grasshopper

3 Extracting tile row guide lines and normals from the surface

4 Batch generation of rows of tiles according to certain predefined regulations

5 Converting the model into a BIM model in Bentley ABD (Figure 16)

6 Finalizing the roof in Bentley ABD and attaching properties needed to each tile

In this case, ridges and other skeleton lines do not have to be "regular", while rows of tiles are reconstructed in a regularized way once those skeletons are extracted and redefined.

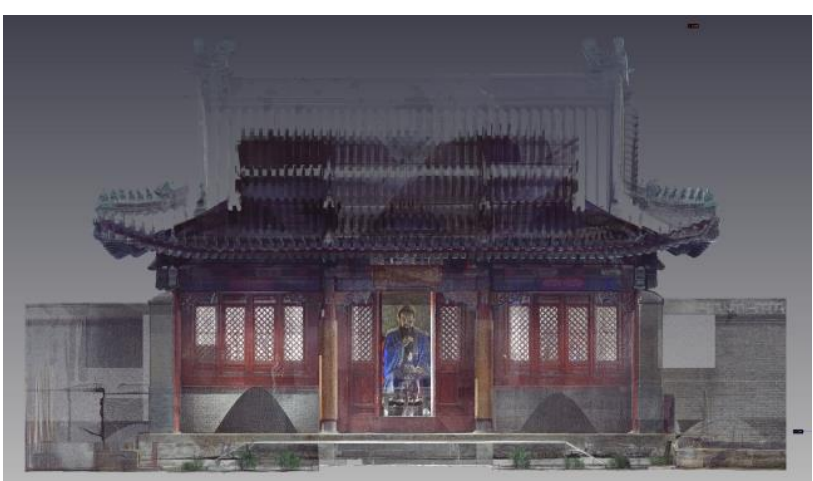

Figure 14. the Main Hall of Lu Ban Shrine, Jizhou, Tianjin, point cloud 


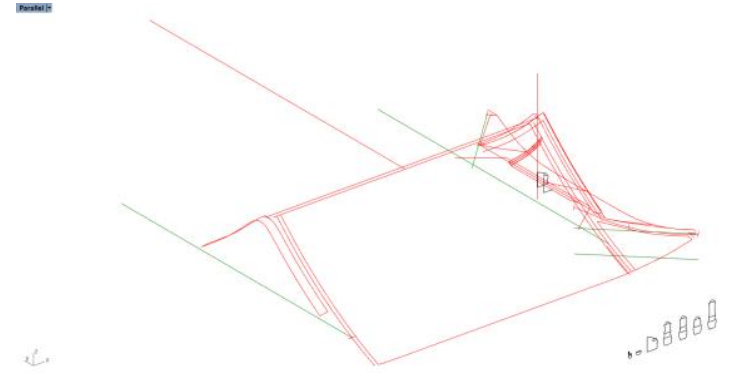

Figure 15. Skeleton lines for the roof of Main Hall of Lu Ban Shrine, Jizhou, Tianjin, extracted from point cloud

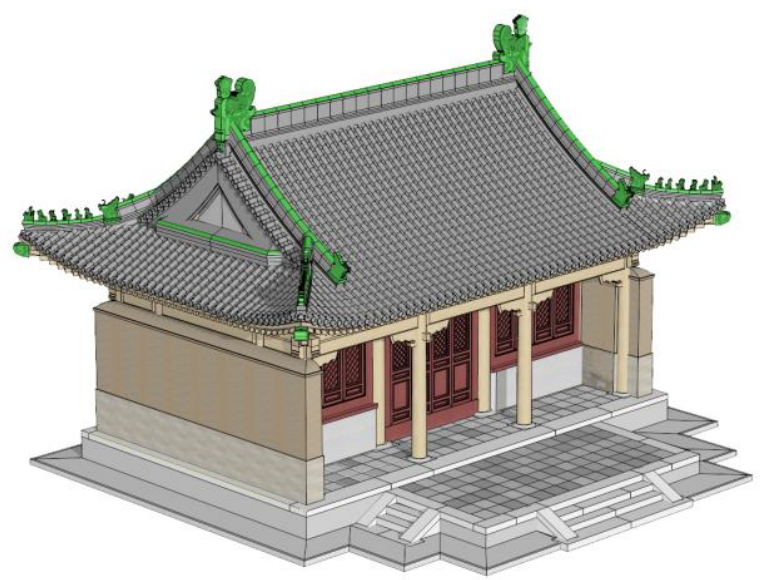

Figure 16. BIM model for the Main Hall of Lu Ban Shrine, Jizhou, Tianjin

\subsection{Regularized Reconstruction for Bracket Sets}

Bracket Sets or Dougong are special articulation in traditional Chinese timber buildings. According to studies concerned, bracket system are highly parametric based on a modular system. Therefore it is possible to reconstructed them in a regularized way absolutely.

Subject: Bracket system from a pattern book (Building regulation of Song Dynasty, Ying Zao Fa Shi)

Objective: regularized Reconstruction bracket members and their combination

Characteristic: Bracket set is usually made up of highly parametric members

\section{Solution:}

1. Acquiring data (including sampling sizes) from point cloud and hand measurement

2. Defining regulations and parameters according to the pattern book and data collected

3. Reconstruction of a parametric model for the bracket in Grasshopper (Figure 17, 18)

4 Converting the model into a BIM model in Bentley ABD

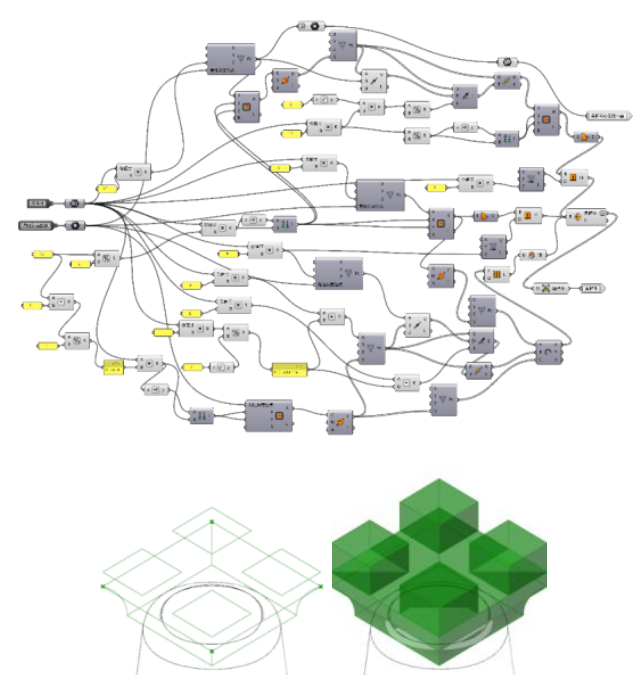

Figure 17. Algorithm battery for bracket set generation

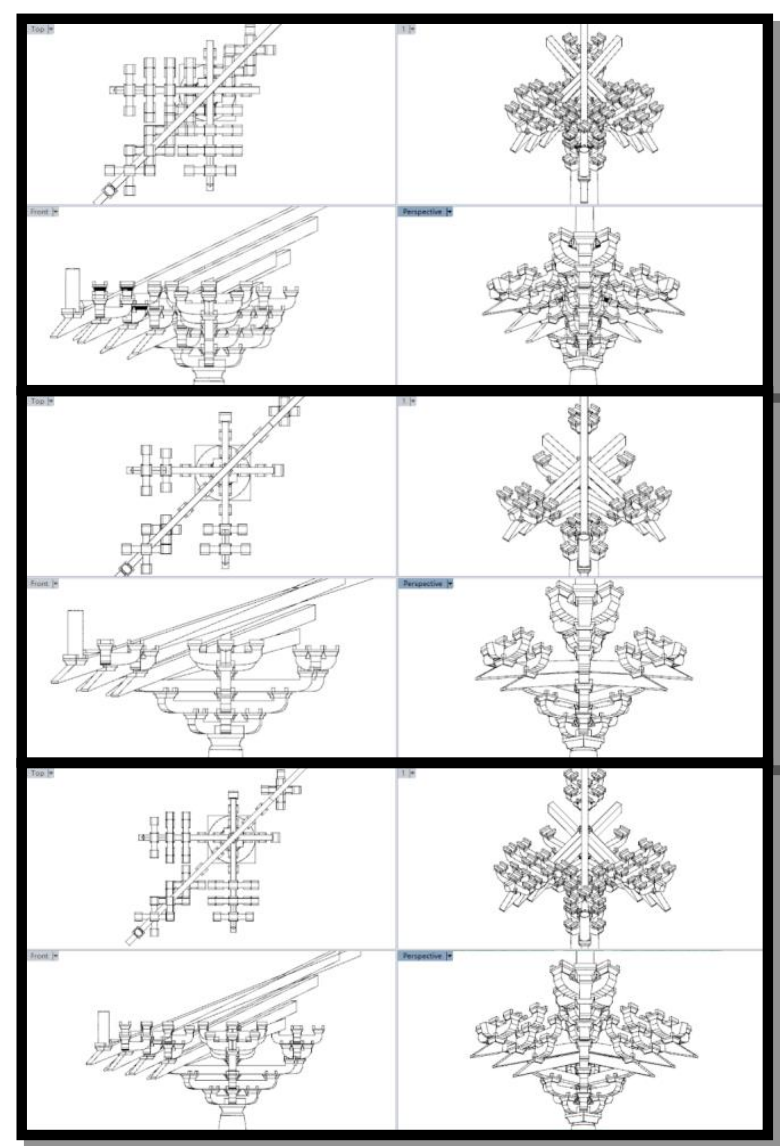

Figure 18. Three variations of bracket sets

\section{CONCLUSION}

Based the three cases above, and our definition of HBIM as an information "index frame" model, it is quite safe to come to conclusions as following:

1. Partial or global regularized reconstruction is available and efficient.

2. Regularized reconstruction can make best use of the advantages of BIM and bypass the disadvantages 
3. To what extent the use of regularized reconstruction is depends on the regularity degree of the subject.

\section{ACKNOWLEDGEMENTS}

This research is partially supported by following institutions: the Palace Museum, China; China Academy of Cultural Heritage; Cultural Heritage Administration of Jizhou District, Tianjin.

\section{REFERENCES}

Dumarçay, J., 1971. Ta Kèv: Etude architecturale du temple. Paris: EFEO.

English Heritage, 2000. Metric Survey Specification for English Heritage. Swindon: English Heritage, NMR Centre.

Wu, C., Li, K., Li, S. et al, 2016. From digitization to informization: discussion on the application of information technology on architectural heritage (in Chinese), China Cultural Heritage, (2), 18-24. 